\title{
Educação e inclusão digital: consistências e fragilidades no empoderamento dos grupos sociais
}

\author{
Education and digital inclusion: consistencies and weaknesses in the \\ empowerment of social groups
}

\author{
Educación e inclusión digital: consistencias y debilidades en el \\ empoderamiento de los grupos sociales
}

\author{
LUCILA PESCE* \\ ADRIANA ROCHA BRUNO**
}

\begin{abstract}
RESUMO - O presente artigo integra o quadro teórico realizado para uma pesquisa em desenvolvimento sobre políticas de inclusão digital e seus desdobramentos na educação formal. Portanto, no tocante ao método, o artigo apresenta-se como pesquisa bibliográfica. O texto busca evidenciar consistências e fragilidades, no âmbito da inclusão digital, mediante discussão centrada em dois campos conceituais: cibercultura e constituição dos sujeitos sociais; inclusão digital e empoderamento. Na argumentação, o artigo defende a ampliação do conceito de inclusão digital, que transcende a fluência tecnológica e o acesso aos recursos tecnológicos e à conexão em rede. A visão ampliada do conceito de inclusão digital ora proposta pertence ao campo mais amplo da inclusão social. Por essa razão, articula-se ao conceito freireano de empoderamento dos grupos sociais, para que estes se percebam como leitores críticos de si e de suas circunstâncias, e possam nelas intervir, com mais consciência e consistência.
\end{abstract}

Palavras-chave - Educação. Inclusão digital. Empoderamento.

\begin{abstract}
This paper integrates the theoretical framework for research conducted about developing policies on digital inclusion and its reflections on formal education. Concerning to the method, the paper presents a literature review. The text seeks to show consistencies and weaknesses in the context of digital inclusion by a discussion centered on two semantic fields: cyberculture and constitution of social subjects; digital inclusion and empowerment. In the discussion, the article argues for the expansion of the concept of digital inclusion that transcends technological fluency and access to technological resources and networking. The expanded concept of digital inclusion belongs to the major field of social inclusion. To do so, it articulates digital inclusion and the Freire's concept of empowerment of social groups, so that they see themselves as critical readers of their circumstances, to intervene in them, with more awareness and consistency.
\end{abstract}

Keywords - Education. Digital inclusion. Empowerment.

RESUMEN - Este trabajo integra el marco teórico de la investigación llevada a cabo en las políticas en materia de inclusión digital y sus desarrollos en la educación formal. Por lo tanto, con respecto al método, el artículo es una revisión de literatura. El texto busca mostrar consistencias y debilidades en el contexto de la inclusión digital mediante la discusión centrada en dos campos semánticos: cibercultura y constitución de sujetos sociales; la inclusión y el empoderamiento digital. En la discusión, el artículo argumenta a favor de la ampliación del concepto de inclusión digital, que trasciende la fluidez tecnológica y el acceso a los recursos tecnológicos y a la conexión de redes. El concepto ampliado de la inclusión digital pertenece a la esfera más amplia de la inclusión social e por esto propone una visión articulada con el concepto freireano de empoderamiento de los grupos sociales, para que ellos sí sitúen como lectores críticos de sí y sus circunstancias, a intervenir en ellas, con más conciencia y coherencia.

Palabras clave - Educación. Inclusión digital. Empoderamiento.

\footnotetext{
* Doutora em Educação pela Pontifícia Universidade Católica de São Paulo (São Paulo, SP, Brasil) e professora na Universidade Federal de São Paulo (São Paulo, SP, Brasil).E-mail: <lucila.pesce@unifesp.br>.

**Doutora em Educação pela Pontifícia Universidade Católica de São Paulo (São Paulo, SP, Brasil) e professora na Universidade Federal de Juiz de Fora (Juiz de Fora, MG, Brasil).E-mail: <adriana.bruno@ufjf.edu.br>.
} 


\section{INTRODUÇÃO}

O presente artigo deriva da pesquisa bibliográfica realizada por uma das autoras que o assinam como parte de uma investigação em desenvolvimento. Já o estudo sobre políticas de inclusão digital e seus desdobramentos na educação está sendo desenvolvido pela outra autora (?), na qualidade de líder de um grupo de pesquisa vinculado ao departamento de educação de uma universidade federal da região Sudeste do país, juntamente com dois pós-graduandos sob sua orientação.

Para os propósitos deste artigo, a discussão concentrase em dois campos conceituais: cibercultura e constituição dos sujeitos sociais; inclusão digital e empoderamento. Estes integram o quadro teórico de referência da pesquisa em desenvolvimento. É apresentado pela aderência com a temática proposta pelo dossiê ao qual este texto se vincula e pela contribuição desta revisão teórica para os estudos e pesquisas sobre inclusão digital.

\section{MÉTOdo}

De acordo com Almeida-Júnior (1989, p. 97-118), a pesquisa bibliográfica consubstancia-se como atividade de localização e consulta de fontes diversas de informação escrita, com o objetivo de coletar dados gerais e/ou específicos a respeito de um determinado tema e se desenvolve a partir das seguintes fases: identificação de fontes seguras, localização dessas fontes e compilação das informações (documentação).

No caso deste artigo, a discussão centrou-se em dois campos conceituais: cibercultura e constituição dos sujeitos sociais; inclusão digital e empoderamento. Para tanto, a revisão de literatura sobre cibercultura ancora-se em pesquisadores de referência internacional, como Serres (2013), Lèvy (1997), Castells (1996; 2012), Manovich (2001), entre outros. No que se refere, especificamente, ao tema "inclusão digital" no contexto nacional, a revisão de literatura ampara-se em um e-book organizado por pesquisadores de expressão na área (PRETO e BONILLA, 2011) e em artigos publicados em periódicos vinculados às bases de dados da SCIELO: Scientific Electronic Library Online. Tais estudos são apresentados em articulação com análises sobre a constituição dos sujeitos sociais e sobre o conceito freireano de empoderamento.

Este estudo bibliográfico, no âmbito da pesquisa mais ampla em que se insere, à discussão conceitual alia-se a exploração de programas de inclusão digital, disponibilizados em sítios eletrônicos, no contexto da educação formal, tais como o Programa Nacional de Tecnologia Educacional (ProInfo); Programa Um computador por Aluno (Prouca); Proinfo Integrado; Banda Larga nas Escolas; Telecentros Comunitários;
Programa de Inclusão Social e Digital. A isso se soma a imersão analítica em três documentos legais referentes à formação docente para o uso pedagógico das Tecnologias Digitais da Informação e Comunicação (TDIC): Parecer CNE/CP 09/2001 (BRASIL, 2001); Resolução CNE/CP 01/2006 (BRASIL, 2001); Plano Nacional de Educação Projeto de Lei no 8.035 de 2010 (BRASIL, 2010).

Amparado em uma perspectiva dialética (SANFELICE, 2005; TRIVIÑOS, 1987), o estudo abrange a observação de recorrências e singularidades dos programas de inclusão digital analisados. Busca evidenciar (dependendo do caso) permanências e mudanças históricas desses programas, de modo a apontar seus limites e possibilidades no âmbito das políticas públicas de inclusão digital.

A supracitada pesquisa mais ampla em que se insere este estudo bibliográfico tem como objeto de investigação as políticas brasileiras de inclusão digital e seus reflexos no âmbito da educação formal.

O texto ergue-se em meio a uma análise, que tenciona dois campos conceituais, na busca de evidenciar consistências e fragilidades afeitas à temática em questão. São eles: cibercultura e constituição dos sujeitos na contemporaneidade; inclusão digital e empoderamento.

\section{Cibercultura e CONSTituição dos SUJEITOS SOCIAIS}

Em relação à constituição do sujeito, este estudo valemo-se de alguns teóricos, dentre os quais Alain Touraine. Na obra Crítica da modernidade (1994), o teórico, ao versar sobre o nascimento do sujeito, assinala que a constituição do sujeito emana da vontade do indivíduo em agir como ator da própria vida, das suas ideias e condutas. Nessa perspectiva, Touraine assevera a "[...] vontade do indivíduo de ser produtor e não somente consumidor de sua experiência individual e de seu meioambiente social" (p. 245). E é revelando o valor da experiência que o estudioso faz um importante alerta: “[...] os sucessos da ação tecnológica não devem fazer com que se esqueça a criatividade do ser humano" (p. 218).

Um teórico brasileiro bastante ocupado com o conceito de sujeito é Pereira (2007). Este pesquisador desvela as questões da subjetividade, indo à etimologia da palavra sujeito: advinda de subjectum (tradução latina do grego hypokeimenon), articulada à noção aristotélica daquilo que está na base, o que porta ou é suporte. Assinala, ainda, que a noção de sujeito é cunhada na Modernidade. Nesse movimento, esclarece que a expressão cartesiana cogito ergo sum (penso, logo existo) desvela o quanto Descartes valoriza o sujeito nos seus processos de interioridade, consciência e imanência. Como não poderia deixar 
de ser, o estudioso resgata também a orientação idealista de Kant, que põe às claras a noção de que o fundamento do objeto está no sujeito, uma vez que o conceito de objeto supõe, estruturalmente, o sujeito. Pereira esclarece que a temática da subjetividade, tão cara à Filosofia, pouco a pouco, mormente a partir da Modernidade, passa a ocupar lugar de destaque no campo das ciências humanas.

Lembrando as dimensões do sujeito - psicocorporal, psicofamiliar, psicossocial, psicoespiritual (não religioso) -, esse teórico advoga em favor de uma pedagogia do sujeito, em que os participantes do processo educacional se construam e se reconheçam como sujeitos do processo do qual fazem parte. Ao lembrar que o sujeito emerge no imbricar de interioridade e exterioridade, Pereira (2007) destaca:

Compartilho [com Alain Touraine, grifo das autoras] a ideia de retorno do sujeito. Mas não nego que o mundo das ideias carece de uma teoria do sujeito. De um sujeito concebido de modo a refletir o momento em que vivemos; um sujeito não fragmentado e não dicotomizado (p. 190).

Outra importante contribuição é trazida por Dora Schnitman (1996), que, ao destacar a relevância da polifonia à constituição do sujeito, esclarece:

Aquilo que se constrói não é homogêneo nem resultado de uma consciência singular, mas um campo de sentido formado por múltiplas interações, por múltiplas vozes: a cultura, o gênero, a localidade, a singularidade contribuíram para essa polifonia. As vozes ligaramse, foram construídas e emergiram como construtoras (p. 248).

A polifonia de que fala Schnitman (1996) emerge com muita força no atual momento histórico, caracterizado a seguir.

Castells (1996), ao refletir sobre os reflexos das redes digitais na sociedade contemporânea, declara que, na cultura da virtualidade real, tem-se assistido à integração da comunicação eletrônica e ao fim da hegemonia da audiência de massa, em virtude do surgimento das redes interativas.

Johnson (1997) advoga em favor da ideia de que as interfaces digitais impactam, de modo significativo, o modo como se age, se raciocina e se comunica. Ao fazêlo, o pesquisador deslinda o papel capital que o design de interface tem exercido na sociedade atual.

Outro pesquisador com argumento convergente é Pierre Lévy (1997), para quem os recursos tecnológicos digitais, analogamente à escrita e à imprensa, ensejam novas formas de pensar o mundo e de se relacionar com a esfera do conhecimento.
Ao situar cultura como prática social, Oliveira (2005) destaca que as produções simbólicas se constituem no cotidiano vivido. Imersa nesse entendimento, a autora sinaliza que as transformações da técnica e dos modos de produção relacionam-se, diretamente, com as transformações do sensorium, entendido como modos de percepção e da experiência social. Essas mudanças trazem profundos impactos sobre a experiência cultural, sobre o modo de vivenciar, perceber e expressar a realidade. Sem se esquecer da exclusão digital de diversos jovens, Oliveira chama a atenção para o sensorium da geração @ e suas características, como o nomadismo, o uso extensivo de linguagens multimidiáticas e a nova percepção de tempo, agora muito mais simultâneo, instantâneo e em fluxo. Esses determinantes circunstanciais acenam para uma plasticidade neuronal dos jovens contemporâneos, que os dota de maior fluência tecnológica. Tais impressões são diariamente ratificadas por todos, quando do convívio com crianças e jovens que não sofrem o processo de exclusão digital, uma das muitas formas de não inclusão social.

Igualmente preocupado com essa temática, Serres (2013), a partir de três questões - o que, a quem e como trabalhar o conhecimento? -, considera sobre as mudanças estruturais por que passam os sujeitos sociais contemporâneos, em especial as crianças e os jovens. Nesse movimento, o teórico, assim como outros tantos, faz menção à relação entre tecnologia e constituição dos sujeitos e das organizações societárias, ao lembrar as duas revoluções que se antecederam à atual: a escrita e a imprensa. Ao fazê-lo, o filósofo deixa clara a ruptura cultural das gerações pré e pós era digital. Ruptura essa que traz vários reflexos aos modos de ser e de estar na sociedade e, em particular, na escola. Tal ruptura atinge as relações que essa geração estabelece com a esfera do conhecimento, com o tempo, com o espaço, com as informações, com a cultura, com os processos de socialização etc. Diante desse cenário, para Serres (ibid.), tudo está por ser reinventado pela nova geração.

E é justamente essa nova geração que vem se valendo, de modo mais contundente, das chamadas redes sociais do ciberespaço. Por meio delas, os seres humanos se divertem e se organizam em nichos de resistência, como nos ensina Habermas (2006). No texto intitulado "O caos da esfera pública", Habermas aponta com muita lucidez as contradições das tecnologias digitais da informação e comunicação (TDICs). De um lado, as TDICs podem promover a ampliação da esfera pública midiática, a condensação das redes de comunicação e o aumento do igualitarismo. De outro, a descentralização dos acessos à informação e a fragmentação dos nexos de comunicação.

A partir do desvelar dessas contradições, julgase oportuno salientar que nem tudo na cibercultura 
acrescenta à plena constituição dos seres humanos. Bons contraexemplos são as mensagens de violência, de pedofilia e de preconceito de toda ordem, veiculadas em diversos sítios eletrônicos da internet. Contudo, as redes sociais, quando utilizadas contra os processos de alienação, podem se consubstanciar como recurso em favor de mudanças, embora não sejam a causa de tais mudanças. Dito de outro modo, as redes sociais carregam contradições, como todo e qualquer aparato simbólico apropriado pelo capital. De um ladoPodem gerar relações sociais planificadas e aligeiradas, de modo a contribuir para a alienação e coisificação do homem. Mas podem, em contrapartida, carregar uma potência para inaugurar um movimento de contraposição ao status quo, na medida em que podem ir à contramão das forças hegemônicas, quando se voltam a formas diferenciadas e inovadoras de participação e de manifestação, de caráter político e ideológico. Tais movimentos se aproximam do que Dussel (2000) alerta, em sua obra Ética da libertação, sobre a exclusão social, quando apresenta a necessidade de se enxergar, compreender e tratar o outro como efetivamente outro - afirmando a razão do outro -, além de respeitálo e se responsabilizar por isso, especialmente em uma sociedade em que o outro foi vitimizado.

Nessa direção, os movimentos de inclusão (social e ou digital) refletem os mecanismos de fortalecimento da hegemonia do capital, na medida em que abrem espaço para as pessoas se inserirem e serem aceitas no que está constituído. Entretanto, esse processo não necessariamente permite a existência de movimentos que aceitem os insurgentes, ou seja, os que questionam ou não querem ser incluídos nos espaços e situações já instituídos pelo capital.

Atento à potência das redes sociais, Castells (2012) traz uma reflexão consistente sobre os movimentos sociais que tomam as ruas, em distintos espaços do planeta, a partir da organização dos sujeitos sociais contemporâneos, por meio das redes sociais. Ao fazê-lo, o pesquisador traz para a cena de discussão a "Primavera Árabe", movimento de manifestações e protestos iniciado na Tunísia, em dezembro de 2010, em levante contra o regime ditatorial que assolava o país, e que ganha força em outros países do Oriente Médio e do norte da África.

O sociólogo lembra também os movimentos sociais ocorridos na Islândia, em favor de uma proposta de criação coletiva da constituição. Nesse resgate, Castells (2012) reflete sobre os vetores transculturais de mudança social, na contemporaneidade, que se valem das TDICs. E prossegue com a análise sobre a revolução egípcia, erguida em meio a um espaço de fluxo e de lugares. Trata-se de revoluções mediadas pela internet, que contam com a participação das mulheres (contrariamente ao lugar periférico que ocupam naquela cultura) na problematização das contradições inerentes à questão islâmica, quando levada a extremo. Atento à geopolítica dessa parte do globo, Castells (2012) resgata o quanto os movimentos árabes valem-se das redes sociais para organizar os levantes das ruas e para burlar a censura à mídia de massa imposta pelos regimes ditatoriais. $\mathrm{O}$ pesquisador prossegue com sua análise sobre a revolução rizomática a que se assiste na contemporaneidade, ao trazer à baila o movimento ocorrido na Espanha, intitulado "Los indignados", que mais tarde recebeu adesão de outros países europeus, como França, Portugal, Inglaterra e Grécia. E não deixa de fora o "Occupy wall street", movimento em rede ocorrido nos Estados Unidos, a partir de setembro de 2011, que se insurge contra a desigualdade econômica e social imposta pelo modelo capitalista hegemônico.

A partir desse cenário mundial, Castells (2012) reflete sobre a possibilidade de os movimentos sociais em rede consubstanciarem-se como um modelo emergente. Ao fazê-lo, deflagra a potência da internet para a promoção da cultura da autonomia (erguida em meio à transição da indignação à esperança) e para o fortalecimento de movimentos sociais em rede, que advogam em favor de uma política reformista.

Nesse movimento analítico, o pesquisador reflete sobre o impacto que as TDICs imprimem à sociedade e aos meios de comunicação. Ao fazê-lo, assevera que, a cada dia, assiste-se à consolidação de novos espaços sociais de interação, ocupação e personalização, isto é, a uma crise nos meios tradicionais de comunicação. E esta situa os sujeitos sociais em posição de passividade em face das novas possibilidades de coautoria e coparticipação ofertadas pelos dispositivos midiáticos do ciberespaço. Nesse sentido, o autor (ibid.) assinala que a política vem sendo afetada pelo enfraquecimento dos meios tradicionais de comunicação, os quais trazem consigo a crise de representação de poder, que encontra eco nos novos espaços sociais em rede.

Para Castells (2012), os movimentos sociais contemporâneos assumem algumas características, tais como os movimentos recentes (de 2007 em diante), que partem das redes digitais e ocupam os espaços urbanos; os movimentos que repudiam a violência e são despojados de lideranças formais e de programas específicos, por vezes com pauta indefinida de objetivos e reivindicações; os movimentos de pessoas que não se sentem representadas pelas atuais instituições democráticas e que têm a indignação como eixo central das demandas por mudanças culturais; e os movimentos de autocomunicação de massa, com capacidade para resistir e renascer a todo instante.

Prosseguindo em sua análise, Castells (2012) pontua que as pessoas que participam desses movimentos estão conectadas em rede de inúmeras formas. Tais movimentos 
travam uma relação até então inusitada com o tempo, assumindo dimensões locais (pois surgem de situações circunscritas) e globais (por ganharem adesão em diversos pontos do planeta com situações circunscritas semelhantes). Por essa razão, para o pensador, tais movimentos sociais são virais (seguindo a lógica das redes). Essa nova forma espacial dos movimentos sociais em rede faz com que o espaço da autonomia ocorra num híbrido de ciberespaço e espaço urbano.

Aprofundando sua análise sobre a emergência dos movimentos sociais em rede, o autor ressalta que se trata de movimentos sem uma liderança formal, posto que a horizontalidade das redes favorece os processos solidários de colaboração. Para Castells, outra importante característica é que, raramente, tais movimentos assumem um caráter programático, à exceção de quando se relacionam diretamente com um objetivo claro, como o clamor da Primavera Árabe pelo fim da ditadura. Tratase, portanto, de movimentos sociais de caráter cívico, que têm o objetivo de promover mudanças nos valores sociais. Todavia, tais movimentos também abarcam a dimensão política, na proposição e na prática de uma democracia direta e em rede. No entendimento do sociólogo, os movimentos sociais em rede assumem um ativismo social, na medida em que almejamuma reforma, no compartilhar da cultura da autonomia, por ele entendida como a matriz cultural fundamental das sociedades contemporâneas.

No Brasil, movimentos como "Ficha Limpa" e "Tarifa Zero", a que se assistiu recentemente, são emblemáticos da potência das agitações sociais em rede para a promoção de mudanças que atendam ao clamor da sociedade.

As considerações até então tecidas põem às claras a impossibilidade de os sujeitos sociais contemporâneos procederem ao exercício pleno da cidadania, se alijados das práticas sociais que se valem dos recursos midiáticos digitais. Corroborando com esse entendimento, Silveira (2008) usa o termo 'cibercidadania' para se referir ao imbricar entre cibercultura e pleno exercício da cidadania na contemporaneidade.

Nesse contexto sociotécnico (MANOVICH, 2001), a Educação pode ocupar um protagonismo, valendo-se de modo cada vez mais intenso e consciente dos recursos midiáticos digitais. Contudo, não são raras as situações em que a plena vivência da cultura digital - na expressão de Bonilla (2010) - não é percebida de modo articulado à plena vivência da cidadania.

Concorda-se com a autora sobre a ideia de que muitos são os desafios que se apresentam à efetiva abertura das escolas para a ampla vivência da cultura digital. Vivência essa que, no entendimento de Bonilla (2010), situa-se como superação da perspectiva instrumental da escola. A pesquisadora, nesse movimento, traz um importante alerta sobre possíveis fatores que dificultam a promoção da plena vivência da cultura digital, por crianças e jovens, no cotidiano das escolas:

[...] a exploração desses ambientes [como redes sociais e games, grifo (das autoras?], para formação da cultura digital, é confundida com 'tolerância', e considerada como algo 'menor', sem valor educacional e que, portanto, deve ser excluída da escola (2010, p. 43).

Se utilizadas, inclusive pela escola, com objetivos que buscam superar a alienação, as TDICs podem ser poderosas aliadas no empoderamento de determinados grupos sociais, como se vê a seguir.

\section{INCLUSÃO DIGITAL E EMPODERAMENTO}

Para o desenvolvimento do campo conceitual afeito ao imbricar entre inclusão digital e empoderamento, construiu-se uma reflexão, em diálogo com teóricos como Bonilla e Preto (2011), Dias (2011), Lemos (2007), Warschauer (2006), Silveira (2008), entre outros, procurando relacionar as considerações dos pesquisadores sobre inclusão digital e sobre o conceito freireano de empoderamento $(1981 ; 1992)$.

Bonilla e Preto (2011), no texto de apresentação da obra por eles organizada - Inclusão digital: polêmica contemporânea -, vinculam o conceito de inclusão digital a uma dimensão que transcende o acesso aos recursos digitais e a fluência tecnológica. Os autores concebem inclusão digital como processo pelo qual os sujeitos sociais, ao se apropriarem dos recursos digitais como coautores, produtores e coparticipantes do processo interacional na cibercultura, utilizam tais recursos como instância transformadora do seu entorno sociocultural.

Em convergência, Lemos (2007) vincula o conceito de inclusão digital a um processo que parte do acesso aos recursos digitais, mas de modo algum se restringe a ele. Mais que isso, para o pesquisador, a inclusão digital efetiva-se em um amplo processo de exercício da cidadania, na sua plenitude, mediante o abarcar de quatro capitais: social, cultural, intelectual e técnico. Seguindo essa mesma linha de raciocínio, no prefácio à obra organizada por Bonilla e Preto (2011), Lemos defende a ideia de que "[...] os programas de inclusão digital devem pensar a formação global do indivíduo para a inclusão social" (2011, p. 16). Argumentando que os sujeitos não se situem apenas como consumidores, mas também como produtores e distribuidores de informação, com autonomia, liberdade e crítica.

Reafirmando a visão ampliada de inclusão digital, Helou et al. (2011) assinalam a necessidade de se fomentar políticas públicas de inclusão digital que estejam atentas às demandas de cada região, tendo em vista as desigualdades sociais e topográficas do país. Ao analisar a 
implantação de dois projetos conjuntos em um município da área rural, os pesquisadores revelam que a internet gratuita, os telecentros e a capacitação da comunidade consubstanciam-se como importantes instâncias que contribuem para a inclusão digital de grupos sociais economicamente desfavorecidos. E concluem sua pesquisa assegurando que o uso das TDICs contribuiu para o pleno exercício da cidadania da comunidade em questão, por promover a socialização dos sujeitos e favorecer o acesso a novos conhecimentos e a diferentes culturas.

Dias (2011) deflagra os múltiplos problemas enfrentados nos telecentros, que, para o seu bom funcionamento, dependem de gestores e monitores capacitados e sensíveis às demandas da comunidade. Ao fazê-lo, desvela os desafios que se impõem aos laboratórios de informática das escolas da rede pública. Amparada nas preocupações de Warschauer (2006) sobre os riscos de a exclusão digital ampliar ainda mais as cisões sociais, situa-se como outra pesquisadora a asseverar que o acesso às TDICs transcende o mero fornecimento de hardware e conexões em rede.

Ao apoiar o conceito ampliado de exclusão digital de Lévy (1997), que desvela o risco do surgimento de novas dependências imperialistas e defende que a inclusão digital esteja de mãos dadas com a autonomia dos indivíduos e grupos sociais, Dias (2011) reflete sobre as múltiplas dimensões da inclusão. Nesse movimento, a pesquisadora esclarece que "[...] massificar a banda larga é essencial para atacar parte do maior núcleo da exclusão digital - a outra parte é a disponibilidade de máquina" (DIAS, 2011, p. 72). Além dessas questões, a autora articula inclusão digital a aspectos como alfabetização digital, cidadania, construção de saberes afeitos à pesquisa e à produção na internet, podendo, em última instância, também abranger linguagem de programação.

Valendo-se de Silveira (2008), para quem a inclusão digital deve estar voltada à dissolução ou à diminuição de quatro assimetrias - acesso à banda larga, bagagem cultural, domínio da língua inglesa e competência técnica -, Dias (ibid.), em sua pesquisa de campo, voltada à inclusão digital de jovens de baixa renda, assinala que as assimetrias que mais pesam para esses jovens são bagagem cultural e domínio da língua inglesa. Seus achados de pesquisa concorrem com as impressões empíricas das autoras, quando do contato com outros jovens oriundos de extratos econômicos desfavorecidos.

Ao discorrer sobre o potencial da comunicação em rede para a construção de um novo ethos societário, Dias (2011) advoga em favor da implantação de programas de inclusão digital de visão abrangente, capazes de situar os sujeitos sociais que deles participam como "[...] autores e atores da Sociedade do Conhecimento" (p. 87).
Preocupado com o fato de que o mero consumo de informação na internet não contribui para a aprendizagem autônoma, Schwartz (2010) fala de um conceito complementar ao da inclusão digital: a emancipação digital. Ao fazê-lo, aponta a importância de se educar para esse fim, levantando um importante alerta: a emancipação digital envolve, necessariamente, a construção colaborativa de conhecimento, para muito além da universalização dos serviços e da formação básica para uso dos recursos digitais.

Schwartz (2010) retoma a preocupação de Freire em trabalhar a alfabetização intimamente articulada à leitura de mundo, para asseverar que a inclusão digital também assuma essa dimensão crítica e não meramente instrumental.

Críticos sobre a literatura ufanista a respeito do papel da TDIC na sociedade contemporânea, Mattos e Chagas (2008) debruçam suas análises sobre as dificuldades da inclusão digital em uma sociedade desigual. Os pesquisadores alertam sobre os riscos de se assistir a uma sociedade brasileira ainda mais assimétrica e excludente, na medida em que a alta desigualdade econômica e social se desdobra em altos índices de exclusão digital. Ao recuperar a literatura da área, que revela que o grau do desenvolvimento econômico determina os limites da dimensão da inclusão social de uma dada sociedade, os autores advertem que a inclusão digital é um fenômeno complexo e abrangente, que transcende o acesso a recursos e conexão. Atentos ao cenário complexo em que se insere a inclusão digital, Mattos e Chagas assinalam a importância de haver um contexto macroestrutural marcado pelo crescimento da renda média (com melhoria do perfil distributivo) e pela melhoria dos padrões educacionais, “[...] para que também as camadas de baixa renda possam ter cada vez maior capacidade de exploração, de interpretação e de uso do enorme mundo de informações disponibilizado pela internet" (2008, p. 89).

Em convergência com os teóricos referendados, Silva et al. (2005) apontam a relação entre inclusão digital, inclusão social e sociedade igualitária, sem deixar de lado a discussão entre inclusão digital e letramento digital desenvolvida por distintos pesquisadores, como Buzato (2003). Para Silva et al. (ibid.), a inclusão digital só se efetiva quando vai além do acesso à informação nos meios digitais; ou seja, quando, a partir desse acesso, atinge a reelaboração do conhecimento. Nessa obra, os autores destacam a importância de a utilização das TDICs voltar-se às demandas comunitárias. Ao fazê-lo, os pesquisadores defendem a ideia de que a cidadania deva partir da esfera da informação, em direção à interpretação crítica da realidade e à consequente construção de sentido. A partir de tais considerações, Silva et al. situam 
a Educação no palco da reflexão, quando resgatam a ideia de a information literacy ser a ela inerente. A Educação, como tal, deve estar no fulcro de uma sociedade incluída.

Soares (2002) também dá um sentido ampliado à inclusão digital, relacionando-o ao conceito de letramento digital e, com ele, às questões críticas e interpretativas que estão além do processo de decodificação de letras e números. A pesquisadora assinala que, com a chegada da internet, iniciam-se novas práticas de leitura e de escrita. Ao fazê-lo, concebe o letramento como fenômeno plural, destacando a relação direta entre as distintas tecnologias de escrita e os vários letramentos. Na mesma medida, múltiplos espaços de escrita e diferentes mecanismos de produção, reprodução e difusão da escrita promovem diversos letramentos.

Como se pode observar a seguir, letramento digital e empoderamento de grupos sociais entrelaçam-se.

$\mathrm{O}$ imbricar entre o conceito freireano de empoderamento e o conceito de inclusão digital ocorre, mormente, na importância auferida à construção da autonomia dos grupos sociais. A seguir, o excerto, destacado da entrevista concedida por Paulo Freire e Ira Shor, é emblemático desse entendimento:

\begin{abstract}
Mesmo quando você se sente, individualmente, mais livre, se esse sentimento não é um sentimento social, se você não é capaz de usar sua liberdade recente para ajudar os outros a se libertarem através da transformação da sociedade, então você só está exercitando uma atitude individualista no sentido do empowerment ou da liberdade (FREIRE e SHOR, 1986, p. 135).
\end{abstract}

Esseconceito freireano de empoderamento (1981; 1986; 1992) não põe luzes à dimensão individual, mas sim à social, por concebê-lo no seio da transformação cultural dos grupos sociais.

Muitos são os estudiosos que destacam o quanto o conceito freireano de empoderamento assume uma perspectiva coletiva, dentre os quais Baquero (2012). Ao salientar que o conceito ampara-se em uma percepção crítica da materialidade histórica dos sujeitos sociais, a pesquisadora esclarece que este tem como objetivo a dimensão coletiva, que emerge para Freire como elemento essencial à promoção das transformações sociais.

O conceito freireano de empoderamento sinaliza o importante papel da Educação, na promoção de práticas sociais contribuintes à construção do capital cultural de grupos sociais economicamente desfavorecidos. Práticas sociais estas que, na atualidade, em grande parte ocorrem num híbrido entre o ciberespaço e os espaços urbanos, como nos ensina Castells (2012).

\section{CONSIDERAÇõES FINAIS}

O presente artigo propôs uma reflexão sobre a problemática concernente ao campo da inclusão digital, percebendo-o como uma das dimensões que integram o campo da inclusão social. Para tanto, construíram-se considerações, a partir de dois campos conceituais, por entender que ambos estejam relacionados a uma visão de inclusão digital que não se restringe à formação dos seres humanos contemporâneos para as atuais demandas do capital. Nessa perspectiva, estruturouse o argumento do estudo, em diálogo com teóricos como Touraine (1994), Pereira (2007), Schnitman (1996), Serres (2013), Castells (1996; 2012), Johnson (1997) e Lévy (1997), entre outros, para analisar a constituição das subjetividades em uma época marcada pela presença marcante das TDICs. Prosseguiu-se com as reflexões a partir das contribuições de Lemos (2007), Preto e Bonilla (2011), Soares (2002), Silva et al. (2005), Dias (2011), Silveira (2008), Warschauer (2006), Schwartz (2010), etc., para examinar o conceito de inclusão digital, articulado ao conceito freireano de empoderamento (1981; 1992).

$\mathrm{O}$ argumento do presente texto ressalta que a reflexão trazida por Castells (2012) sobre os movimentos sociais em rede converge com o conceito freireano de empoderamento, na medida em que ambos se referem à incorporação de artefatos culturais e de saberes construídos socialmente. Estes, capazes de auferir aos indivíduos contemporâneos o lugar de sujeitos sociais, construtores da sua própria história e promotores coletivos de mudanças que contribuam para a emancipação dos grupos sociais. Em outras palavras, o pesquisador (2012) considera que a potência das redes sociais para a emancipação dos sujeitos sociais contemporâneos de certo modo materializa, em versão atualizada e atinente aos determinantes circunstanciais de hoje em dia, o que Freire, a seu tempo, sinalizava, em relação ao empoderamento de grupos sociais. Castells deflagra exemplos atuais de uma inclusão digital que efetivamente se apresenta como processo social de conscientização e emancipação, em aderência com as premissas freireanas.

Os textos analisados no presente artigo, afeitos ao campo da inclusão digital, destacam, em uníssono, que tal conceito deve transcender a visão restrita ao acesso (aos recursos digitais e à conexão em rede) e circunscrita à fluência digital. Em concordância com os pesquisadores ora referendados, constata-se que a inclusão digital erigese como uma das facetas da inclusão social na atualidade. E, como tal, assinala-se a necessidade de que a problemática concernente à inclusão digital seja enfrentada. O que significa ir além de uma visão restritiva (acesso e fluência 
tecnológica), sob o risco de se promover processos de coisificação dos seres humanos, ao situá-los como meros consumidores de informação veiculada na internet. E, possivelmente, posicioná-los como sujeitos vulneráveis à alienação promovida por conteúdo eletrônico, que em nada acrescenta à plena formação humana.

Se o intento é a incorporação dos recursos midiáticos digitais como contribuinte da construção de relações sociais promotoras da conscientização e da emancipação, é preciso ampliar o conceito restritivo de inclusão digital, articulando-o ao conceito freireano de empoderamento dos grupos sociais, para que estes se percebam como leitores críticos de si e de seus determinantes circunstanciais.

É imperioso trabalhar a inclusão digital como pertencente ao campo maior da inclusão social, em um movimento capaz de promover a emancipação dos sujeitos sociais envolvidos, para que eles se situem, coletivamente, como leitores e construtores de suas circunstâncias históricas.

A intenção de situar a inclusão digital nessa perspectiva ampliada e articulada ao conceito freireano de empoderamento vale-se da polifonia humana (SCHNITMAN, 1996). Para, com isso, ir ao encontro da constituição de subjetividades mais próximas ao campo da emancipação, quando os sujeitos sociais refletem sobre o mundo em que vivem, para nele atuarem, com mais consciência coletiva e de modo mais consistente.

Foram utilizadas neste artigo as palavras de Preto, Souza e Rocha (2011, p. 179), por representarem o mesmo entendimento das autoras: ente

\begin{abstract}
Entendemos que, para o movimento de inclusão digital, faz-se necessário a implementação de políticas públicas articuladas entre si, nas esferas públicas municipal, estadual e federal, para que possam ser desencadeadas ações que superem ideias reducionistas e assistencialistas, sem comprometimento com as questões estruturais da sociedade. Aliado a isso, é necessário também uma participação efetiva dos sujeitos envolvidos, permitindo-lhes uma participação mais forte, ou seja, o acesso a atributos fundamentais da construção da cidadania.
\end{abstract}

Nesse cenário, a Educação, em sentido lato e, particularmente, o campo da formação de professores da Educação Básica têm uma importante contribuição a dar, para que o conceito ampliado de inclusão digital seja efetivamente implantado no seio das escolas. No campo das práticas sociais escolares, o uso das TDICs, se mediado pelos professores com intencionalidade emancipatória, em muito tem a contribuir com a mudança do status quo.

\section{REFERÊNCIAS}

ALMEIDA JÚNIOR, João Baptista de. O estudo como forma de pesquisa. In: CARVALHO, Maria Cecília de. Metodologia científica, fundamentos e técnicas: construindo o saber. 12. ed. Campinas, SP: Papirus, 1989. p. 97-118.

BAQUERO, Rute. Empoderamento: instrumento de emancipação social? Uma discussão conceitual. Revista Debates (UFRGS), Porto Alegre, v. 6, n. 1, p. 173-187, jan.abr. 2012. Disponível em: <http://seer.ufrgs.br/debates/article/ viewFile/26722/17099>. Acesso em: 13 abr. 2014.

BONILLA, Maria Helena. Políticas públicas para inclusão digital nas escolas. Motrivivência, ano XXII, n. 34, p. 40-60, jun. 2010. Disponível em: <http://www.periodicos.ufsc.br/ index.php/motrivivencia/article/view/17135>. Acesso em: 13 abr. 2014.

BONILLA, Maria Helena; PRETO, Nelson (Org.). Inclusão digital: polêmica contemporânea. Salvador: EDUFBA, 2011. Disponível em: https://repositorio.ufba.br/ri/bitstream/ ri/4859/1/repositorio-Inclusao\%20digital-polemica-final.pdf $>$. Acesso em: 13 abr. 2014.

BRASIL. Parecer CNE/CP 09/2001, de 8 de maio de 2001. Institui as Diretrizes Curriculares Nacionais para a formação de professores de Educação Básica, em nível superior, curso de licenciatura, de graduação plena. Brasília, DF: Ministério da Educação, 8 maio 2001. Disponível em: $<$ http://portal.mec.gov. br/cne/arquivos/pdf/009.pdf >. Acesso em: 13 abr. 2014.

BRASIL. Resolução CNE/CP 01/2006, de 16 de maio de 2006. Institui as Diretrizes Curriculares Nacionais para o curso de graduação em Pedagogia, licenciatura. Brasília, DF: Ministério da Educação, 16 maio 2006. Disponível em: <http://portal. mec.gov.br/cne/arquivos/pdf/rcp01_06.pdf $>$. Acesso em: 13 abr. 2014.

BRASIL. Plano Nacional de Educação - Projeto de Lei no 8.035 de 2010. Aprova o Plano Nacional de Educação para o decênio 2011-2020 e dá outras providências. Brasília, DF: MEC, 2010. Disponível em: <http://www.camara.gov.br/sileg/ integras/831421.pdf>. Acesso em: 13 abr. 2014.

BUZATO, Marcelo. Letramento digital abre portas para o conhecimento [11 jan. 2003]. Entrevistadora: Olivia Rangel Joffily. EducaRede. Disponível em: $<\mathrm{http}: / / \mathrm{www}$.educarede. org.br/educa/html/index_busca.cfm>. Acesso em: 13 abr. 2014.

CASTELLS, Manuel. The rise of network society. Oxford: Blackwell Publishers, 1996.

CASTELLS, Manuel. Redes de indignación y esperanza: los movimientos sociales en la era de Internet. Tradução de Maria Hernández Díaz. Madrid: Alianza Editorial, 2012.

DIAS, Lia Ribeiro. Inclusão digital como fator de inclusão social. In: PRETO, Nelson; BONILLA, Maria Helena (Org.). Inclusão digital: polêmica contemporânea. Salvador: EDUFBA, 2011. p. 61-90. Disponível em: <https://repositorio. ufba.br/ri/bitstream/ri/4859/1/repositorio-Inclusao\%20digitalpolemica-final.pdf $>$. Acesso em: 13 abr. 2014.

DUSSEL, Enrique. Ética da libertação na idade da globalização e da exclusão. Petrópolis: Vozes, 2000.

FREIRE, Paulo. Pedagogia do oprimido. Rio de Janeiro: Paz e Terra, 1981. 
FREIRE, Paulo. Pedagogia da esperança: um reencontro com a pedagogia do oprimido. Rio de Janeiro: Paz e Terra, 1992.

FREIRE, Paulo; SHOR, Ira. Medo e ousadia: o cotidiano do professor. Rio de Janeiro: Paz e Terra, 1986.

HABERMAS, Jürgen. O caos da esfera pública. Jornal Folha de São Paulo, São Paulo, 13 ago. 2006. Caderno Mais, p. 4-5.

HELOU, Ângela et al. Políticas públicas de inclusão digital. RENOTE - Revista Novas Tecnologias na Educação, Porto Alegre, v. 9, n. 1, p. 1-10, 2011. Disponível em: <seer.ufrgs. br/renote/article/download/21920/12720>. Acesso em: 13 abr. 2014.

JOHNSON, Steven. Interface culture: how new technology transforms the way we create and communicate. New York (USA): Harper Edge (Harper Collins), 1997.

LEMOS, André (Ed.). Cidade digital: portais, inclusão e redes no Brasil. Salvador: Edufba, 2007.

LEMOS, André. Prefácio. In: PRETO, Nelson; BONILLA, Maria Helena (Org.). Inclusão digital: polêmica contemporânea. Salvador: EDUFBA, 2011. p. 15-21. Disponível em: <https:// repositorio.ufba.br/ri/bitstream/ri/4859/1/repositorio-Inclusao \%20digital-polemica-final.pdf>. Acesso em: 13 abr. 2014.

LÉVY, Pierre. Cyberculture. Paris: Éditions Odile Jacob, 1997.

MANOVICH, Lev. The language of new media. Cambridge: The MIT Press, 2001.

MATTOS, Fernando Augusto; CHAGAS, Gleidson José do Nascimento. Desafios para a inclusão digital no Brasil. Perspect. Ciênc. Inf., Belo Horizonte, v. 13, n. 1, p. 67-94, jan.-abr. 2008. Disponível em: <http://www.scielo.br/pdf/pci/ v13n1/v13n1a06.pdf>. Acesso em: 13 abr. 2014.

OLIVEIRA, Rita de Cássia. Cibercultura, cultura audiovisual e sensorium juvenil. In: LEÃO, Lucia. (Org.). O chip e o caleidoscópio: reflexões sobre as novas mídias. São Paulo: SENAC, 2005. p. 495-503.

PEREIRA, Potiguara Acácio. Considerações em torno a uma concepção do sujeito. In: MORENO, Leda Virgínia Alves; ROSITO, Margaréte May Berkenbrock (Org.). O sujeito na educação e saúde: desafios na contemporaneidade. São Paulo: Loyola, 2007. p. 179-195.

PRETO, Nelson; BONILLA, Maria Helena (Org.). Inclusão digital: polêmica contemporânea. Salvador: EDUFBA, 2011. p. 163-182. Disponível em: <https://repositorio.ufba.br/ri/ bitstream/ri/4859/1/repositorio-Inclusao\%20digital-polemicafinal.pdf>. Acesso em: 13 abr. 2014.

PRETO, Nelson; SOUZA, Joseilda Sampaio; ROCHA, Telma Brito. Tabuleiro digital: uma experiência de inclusão digital em ambiente educacional. In: PRETO, Nelson; BONILLA, Maria Helena (Org.). Inclusão digital: polêmica contemporânea.
Salvador: EDUFBA, 2011. p. 163-182. Disponível em: $<$ https://repositorio.ufba.br/ri/bitstream/ri/4859/1/repositorioInclusao\%20digital-polemica-final.pdf $>$. Acesso em: 13 abr. 2014.

SANFELICE, José Luís. Dialética e pesquisa em educação. In: LOMBARDI, José Claudinei; SAVIANI, Dermeval (Org.). Marxismo e educação: debates contemporâneos. Campinas, SP: Autores Associados, 2005. p. 69-94.

SCHNITMAN, Dora Fried. Metáforas da mudança: terapia e processo. In: SCHNITMAN, Dora Fried (Org.). Novos paradigmas, cultura e subjetividade. Porto Alegre: Artes Médicas, 1996. p. 244-253.

SCHWARTZ, Gilson. Educação como produção colaborativa de conteúdo. In: XI ENCONTRO NACIONAL DAS ESCOLAS DE GOVERNO, 11, 2010, São Paulo. Anais eletrônicos. São Paulo: Fundap, 2010. Disponível em: $<$ http://www.fundap. sp.gov.br/egdialogal/pdf/Apresenta $\% \mathrm{C} 3 \% \mathrm{~A} 7 \% \mathrm{C} 3 \% \mathrm{~A} 3 \mathrm{o} \% 20$ -\%20texto\%20Gilson\%20Schuartz\%2009_06.pdf>. Acesso em: 13 abr. 2014.

SERRES, Michel. Polegarzinha. Tradução de Jorge Bastos. Rio de Janeiro: Bertrand Brasil, 2013.

SILVA, Helena et al. Inclusão digital e educação para a competência informacional: uma questão de ética e cidadania. Ci. Inf., Brasília, v. 34, n. 21, p. 28-36, jan.-abr. 2005. Disponível em: <http:/www.scielo.br/scielo.php?script=sci arttext\&pid=S0100-19652005000100004\&nrm=iso\&tlng=pt $>$. Acesso em: 13 abr. 2014.

SILVEIRA, Sérgio Amadeu. A noção de exclusão digital diante das exigências de uma cibercidadania. In: HETKOWSKI, Tânia Maria (Org.). Políticas públicas \& inclusão digital. Salvador: EDUFBA, 2008.

SOARES, Magda. Novas práticas de leitura e escrita: letramento na cibercultura. Revista Educação e Sociedade, Campinas, v. 23, n. 81, p. 143-160, 2002. Disponível em: <http://www.scielo. br/pdf/es/v23n81/13935.pdf>. Acesso em: 13 abr. 2014.

TOURAINE, Alain. Nascimento do sujeito. In: TOURAINE, Alain. Crítica da Modernidade. 4ª ed. Petrópolis: Vozes, 1994. p. 211-370.

TRIVIÑOS, Augusto. O materialismo histórico. In: TRIVIÑOS, Augusto. Introdução à pesquisa em ciências sociais: a pesquisa qualitativa em educação. São Paulo: Atlas, 1987. p. 49-74.

WARSCHAUER, Mark. Tecnologia e inclusão social: a exclusão digital em debate. São Paulo: Editora Senac, 2006.

Artigo recebido em setembro 2015.

Aprovado em novembro 2015. 